NASA Technical Memorandum 103287

\title{
Viscoplastic Analysis of an Experimental Cylindrical Thrust Chamber Liner
}
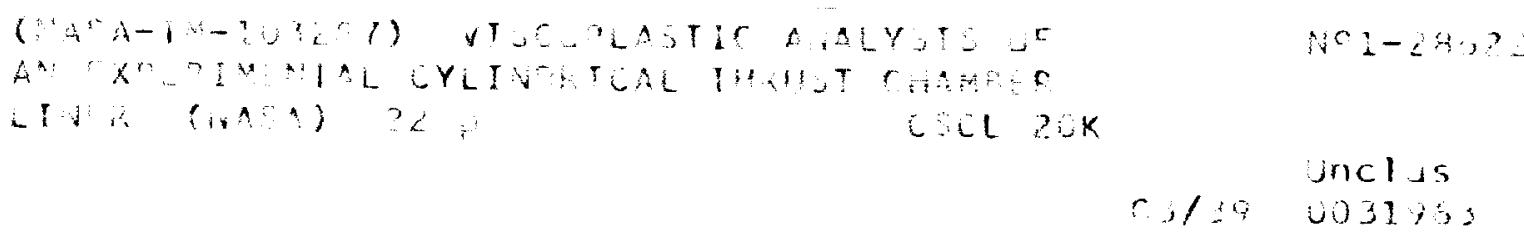

Vinod K. Arya

University of Toledo

Toledo, Ohio

and

Steven M. Arnold

Lewis Research Center

Cleveland, Ohio 



\title{
VISCOPLASTIC ANALYSIS OF AN EXPERIMENTAL CYLINDRICAL THRUST CHAMBER LINER
}

\author{
Vinod K. Arya* \\ University of Toledo \\ Toledo, Ohio 43606 \\ and \\ Steven M. Arnold \\ National Aeronautics and Space Administration \\ Lewis Research Center \\ Cleveland, Ohio 44135
}

\section{Summary}

A viscoplastic stress-strain analysis of an experimental cylindrical thrust chamber is presented. A viscoplastic constitutive model incorporating a single internal state variable that represents kinematic hardening was employed to investigate whether such a viscoplastic model could predict the experimentally observed behavior of the thrust chamber. Two types of loading cycles were considered: a short cycle of 3.5-sec duration that corresponded to the experiments, and an extended loading cycle of 485.1-sec duration that is typical of the Space Shuttle Main Engine (SSME) operating cycle. The analysis qualitatively replicated the deformation behavior of the component as observed in experiments at NASA Lewis Research Center. These experiments were designed to simulate the SSME operating conditions. The analysis also showed that the mode and location of failure in the component may depend on the loading cycle. The results indicate that using viscoplastic models for structural analysis can lead to a more realistic life assessment of thrust chambers.

\section{Introduction}

Progressive deformation and thinning of coolant-channel walls in high-pressure, reusable rocket thrust chambers have been observed during operation of engines such as the Space Shuttle Main Engine (SSME). This inelastic ratcheting behavior is attributed to the significant, thermally induced inelastic

*NASA Resident Research Associate at Lewis Research Center. strains that occur in the hot-gas-side wall during cyclic firing, as well as to the biasing pressure differential across the wall. After numerous thermal cycles, ratcheting strains accumulate to the extent that cracks form (i.e., failure occurs) in the cooling passage wall. Numerous analytical and experimental studies have been undertaken in recent years to examine this phenomenon (refs. 1 to 5 ).

For an accurate estimation of the life of thrust chambers, a realistic inelastic stress-strain analysis is required. Conventional inelastic analyses of components treat the plastic (timeindependent) and creep (time-dependent) strains as independent noninteracting entities; these are inadequate for this application, since at elevated temperatures, interactions are known to exist between plastic and creep strains within metallic materials (ref. 6). Alternatively, unified viscoplastic analyses provide realistic descriptions of high-temperature inelastic behavior of materials, in that all inelastic strains (e.g., creep, plastic, relaxation, and their interactions) are accounted for as a single, time-dependent quantity.

In the present study a unified viscoplastic finite element stress-strain analysis was made of an experimental thrust chamber composed of NARloy-Z, a copper-based alloy. The objective of this study was twofold: (1) to qualitatively predict the experimentally verified thinning of the cooling passage and the so-called "dog house" effect (see ref. 2) by using a viscoplastic model put forth by Robinson (ref. 7); and (2) to investigate the influence of loading cycle duration on the structural response of the cylindrical chamber. To achieve the second objective, two types of thermomechanical loading cycles (see table I) were employed-one corresponding to the experimental simulations and one being more typical of the cycle seen by the SSME. 
TABLE I -CYCLIC TEMPERATURE AND PRESSURE LOADING HISTORIES

[From Ref. 3.]

(a) Duration of Regions

\begin{tabular}{|c|r|r|}
\hline \multirow{2}{*}{ Region } & \multicolumn{2}{|c|}{ Cycle time, sec } \\
\cline { 2 - 3 } & Short & Extended \\
\hline I & 0.10 & 22.50 \\
II & .90 & .90 \\
III & .80 & 180.00 \\
IV & .45 & .45 \\
V & 1.25 & 281.25 \\
\hline Total cycle & & \\
time & 3.50 & 485.10 \\
\hline
\end{tabular}

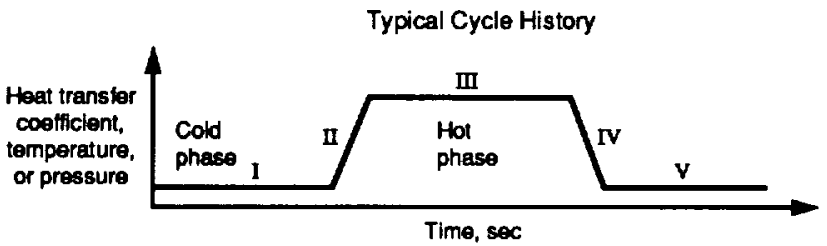

(b) Cycle Phase

\begin{tabular}{|c|c|c|}
\hline & Cold & Hot \\
\hline $\begin{array}{l}\text { Hot-gas-side heat transfer coefficient, } \\
\text { W/ } \mathrm{cm}^{2}-\mathrm{K}\left(\mathrm{Btu} / \mathrm{in}^{2}{ }^{2} \text {-sec-R) }\right.\end{array}$ & 0 & $2.02(0.00685)$ \\
\hline $\begin{array}{l}\text { Hot-gas-side adiabatic wall } \\
\text { temperature, } K\left({ }^{\circ} R\right)\end{array}$ & $278(500)$ & $3364(6055)$ \\
\hline $\begin{array}{l}\text { Hot-gas-side wall pressure, } \\
\mathrm{kN} / \mathrm{m}^{2} \text { (psia) }\end{array}$ & $96.5(14.0)$ & $2780(403)$ \\
\hline $\begin{array}{l}\text { Coolant-side heat transfer coefficient, } \\
\text { W/cm } \mathrm{cm}^{2}-\mathrm{K}\left(\mathrm{Btu} / \mathrm{in}^{2}{ }^{2}-\mathrm{sec}-\mathrm{R}\right)\end{array}$ & $10.2(0.0345)$ & $4.83(0.0164)$ \\
\hline Coolant-side bulk temperature, $\mathrm{K}\left({ }^{\circ} \mathrm{R}\right)$ & $28(50)$ & $50(90)$ \\
\hline $\begin{array}{l}\text { Coolant-side wall pressure, } \\
\mathrm{kN} / \mathrm{m}^{2} \text { (psia) }\end{array}$ & $5100(740)$ & $6550(950)$ \\
\hline
\end{tabular}

A cross section of the experimental cylinder wall, which contains 72 cooling channels, is shown in figure 1 . The shaded area in the figure depicts the segment of the component that was modeled to perform the thermal and structural analyses. The cyclic thermal and pressure loadings (ref. 3) shown in table I lead progressively to a deformed segment that results in the "dog house" effect noted in reference 2 . Figure 2, which shows this dog house, illustrates how the component fails by thinning of the cooling channel wall and eventual tensile rupture. Further details of experiments and apparatus can be found in references 2 and 3.

This paper begins with a brief description of Robinson's viscoplastic model and the finite element analysis that was performed. Results are then presented and discussed, and conclusions are drawn. Future work is suggested.

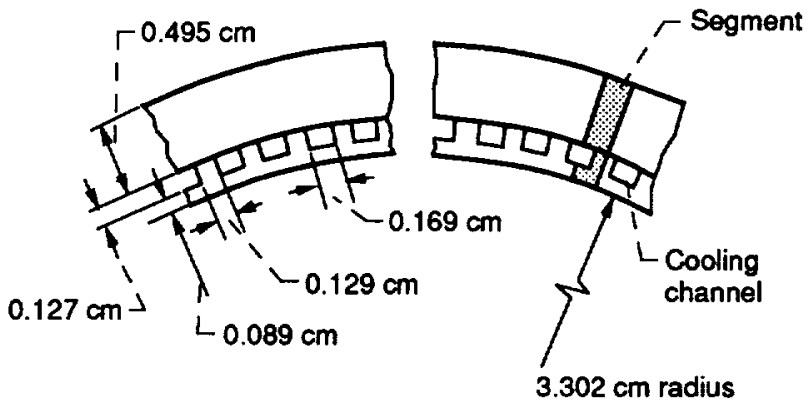

Figure 1.-Cylinder wall cross section showing analyzed segment and dimensions.

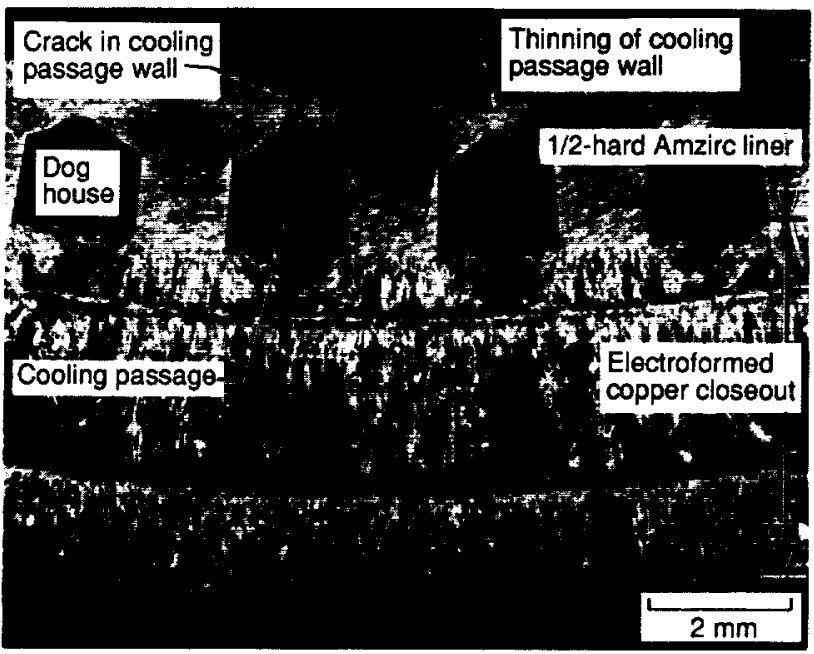

Figure 2.-Cross section of 1/2-hard Amzirc cylinder at the throat plane after 393 thermal cycles.

\section{Robinson's Viscoplastic Model}

Robinson's model (ref. 7) employs a dissipation potential to derive the flow and evolutionary laws for the inelastic strain and internal state variables. The model incorporates a single internal state variable representing kinematic hardening. The material behavior is elastic for all the stress states within the dissipation potential and is viscoplastic for the stress states outside. A small displacement and a small strain formulation are employed.

The total strain rate $\dot{\epsilon}_{i j}$ is decomposed into elastic $\dot{\epsilon}_{i j}^{e l}$, inelastic $\dot{\epsilon}_{i j}^{i n}$ (including plastic, creep, relaxation, etc.), and thermal $\dot{\epsilon}_{i j}^{t h}$ strain-rate components. Thus

$$
\dot{\epsilon}_{i j}=\dot{\epsilon}_{i j}^{e l}+\dot{\epsilon}_{i j}^{i n}+\dot{\epsilon}_{i j}^{i h} \quad(i, j=1,2,3)
$$

The elastic strain rate for an isotropic material is governed by Hooke's law:

$$
\dot{\epsilon}_{i j}^{e l}=\frac{1+\nu}{E} \dot{\sigma}_{i j}-\frac{\nu}{E} \dot{\sigma}_{k k} \delta_{i j}
$$


where $E$ is the Young's modulus, $\nu$ is the Poisson's ratio, and $\sigma_{i j}$ is the stress. The repeated subscripts in equation (2) and elsewhere imply summation over their range, and $\delta_{i j}$ is the Kronecker delta function. A dot over a symbol denotes its derivative with respect to time $t$.

The nonisothermal multiaxial inelastic constitutive equations for the model are given below:

\section{Flow Law}

$\dot{\epsilon}_{i j}^{i n}=\left\{\begin{array}{c}\frac{A F^{\eta} \Sigma_{i j}}{\sqrt{J_{2}}} \quad F>0 \text { and } S_{i j} \Sigma_{i j}>0 \\ 0 \quad F \leq 0 \text { or } F<0 \text { and } S_{i j} \Sigma_{i j} \leq 0\end{array}\right.$

\section{Evolutionary Law}

$\dot{a}_{i j}= \begin{cases}\frac{H}{G^{\beta}} \dot{\epsilon}_{i j}^{i n}-\frac{R G^{m-\beta}}{\sqrt{I_{2}}} a_{i j} & G<G_{o} \text { and } S_{i j} a_{i j}>0 \\ \frac{H}{G_{o}^{\beta}} \dot{\epsilon}_{i j}^{i n}-\frac{R G_{o}^{m-\beta}}{\sqrt{I_{2}}} a_{i j} & \begin{array}{l}G \leq G_{o} \\ \text { or } G>G_{o} \text { and } S_{i j} a_{i j} \leq 0\end{array}\end{cases}$

where

$$
\left.\begin{array}{c}
F=\frac{J_{2}}{K^{2}}-1 \\
G=\frac{I_{2}}{K_{o}^{2}} \\
J_{2}=\frac{1}{2} \Sigma_{i j} \Sigma_{i j} \\
I_{2}=\frac{1}{2} a_{i j} a_{i j} \\
\Sigma_{i j}=S_{i j}-a_{i j} \\
S_{i j}=\sigma_{i j}-\frac{1}{3} \sigma_{k k} \delta_{i j} \\
a_{i j}=\alpha_{i j}-\frac{1}{3} \sigma_{k k} \delta_{i j}
\end{array}\right\}
$$

In the preceding equation, $S_{i j}$ is the deviatoric stress, and $a_{i j}$ and $K$ are the internal state variables. The variable $\alpha_{i j}$, called the back stress, accounts for the kinematic hardening, whereas $K$, taken here to be a constant, is called the drag stress and represents the isotropic hardening of the material. The value of $K$ at the reference temperature is denoted by $K_{o}$, and the minimum value attainable by $G$ is denoted by $G_{o}$. The inequalities in equations (3) and (4) define boundaries across which the flow and evolutionary laws change form discontinuously. To facilitate the numerical computations, these boundaries are smoothed by using a spline function given in the next section. Seven numerical parameters are required to characterize a given material. These parameters are $A, n, m$, $H, R, G_{o}$, and $K\left(K_{o}\right)$. The values of these parameters for the

\begin{tabular}{|c|c|}
\hline Parameter & Value \\
\hline$A$ & $1.385 \times 10^{-8}$ \\
\hline$n$ & 4 \\
\hline$m$ & 4.365 \\
\hline$\beta$ & $0.533 \times 10^{-6} \mathrm{~T}^{2}+0.8$ \\
\hline$Q_{o}$ & 40000 \\
\hline$T_{o}$ & $811 \mathrm{~K}\left(1000^{\circ} \mathrm{F}\right)$ \\
\hline$G_{0}$ & 0.04 \\
\hline$K^{2}$ & $69.88-0.067 \mathrm{~T}$ \\
\hline$K_{o}$ & $K\left(T_{0}\right)$ \\
\hline$H$ & $\left(1.67 \times 10^{4}\right)(6.895)^{\beta+1} /\left(3 \mathrm{~K}_{0}^{2}\right)$ \\
\hline$R$ & $\left(2.19 \times 10^{-3}\right)(6.895)^{l+\beta-m}\left(3 K_{0}^{2}\right)^{m-\beta}$ \\
\hline & $\times \exp \left[Q_{0}\left(\frac{1}{T_{0}}-\frac{1}{T}\right)\right]$ \\
\hline E & $1.47 \times 10^{5}-70.5 \times \mathrm{T}$ \\
\hline$\nu$ & 0.34 \\
\hline
\end{tabular}
copper alloy NARloy-Z, taken from reference 8 , are listed in table II.

TABLE II. - VALUES OF MATERIAL PARAMETERS ${ }^{a}$ FOR ROBINSON'S MODEL

[From ref. 8.]

\section{Spline Function}

The discontinuous boundaries in Robinson's viscoplastic model should be smoothed to facilitate numerical computations. This smoothing is achieved by defining a "spline function" $P(x)$ (refs. 7 and 9) on the interval $(-1,1)$ as 


$$
P(x)= \begin{cases}\frac{(1+x)^{2}}{2} & -1 \leq x<0 \\ 1-\frac{(1-x)^{2}}{2} & 0 \leq x \leq 1 \\ 1 & x>1 \\ 0 & x<-1\end{cases}
$$

\section{Analyses}

The details of the finite element model, and thermal and stress analyses are provided in this section.

\section{Finite Element Model}

Figure 3 depicts the finite element model used for the thermal and stress analyses. It consists of 35 elements and 54 nodes. To facilitate a quasi-three-dimensional analysis, generalized plane strain elements were used to model the smallest repeating segment of the cylinder wall. Because the wall was symmetrical, only one-half of a cooling channel was modeled.

\section{Thermal Analysis}

In reference 2, the thermal analyzer program SINDA (ref. 10) was used to perform the thermal analysis and to generate the time-dependent cross-sectional temperatures. Time-dependent hot-gas-side and coolant-side boundary conditions were input to the SINDA program to obtain the temperature profile as a function of time. To estimate the quantities for which no experimental data were available, some assumptions and approximations were made in the thermal analysis. Complete details of the thermal analysis are provided in reference 2 .

\section{Finite Element Analysis}

By employing the finite element program MARC (ref. 11) and a numerical solution procedure put forth by Arya et al. (refs. 12 and 13), a stress-strain analysis of the cylindrical thrust chamber was performed. A self-adaptive integration strategy, based on the explicit forward Euler method and described in reference 14 , was employed for the time integration of the nonlinear and mathematically 'stiff" constitutive equations of the viscoplastic model. The integration strategy is easy to implement, and it has been employed successfully for the solution of problems involving complex geometries and loadings (refs. 4 and 15).

The finite element thermostructural analysis was performed with the time-dependent temperature distribution obtained from the thermal analysis described in the preceding section. Time-

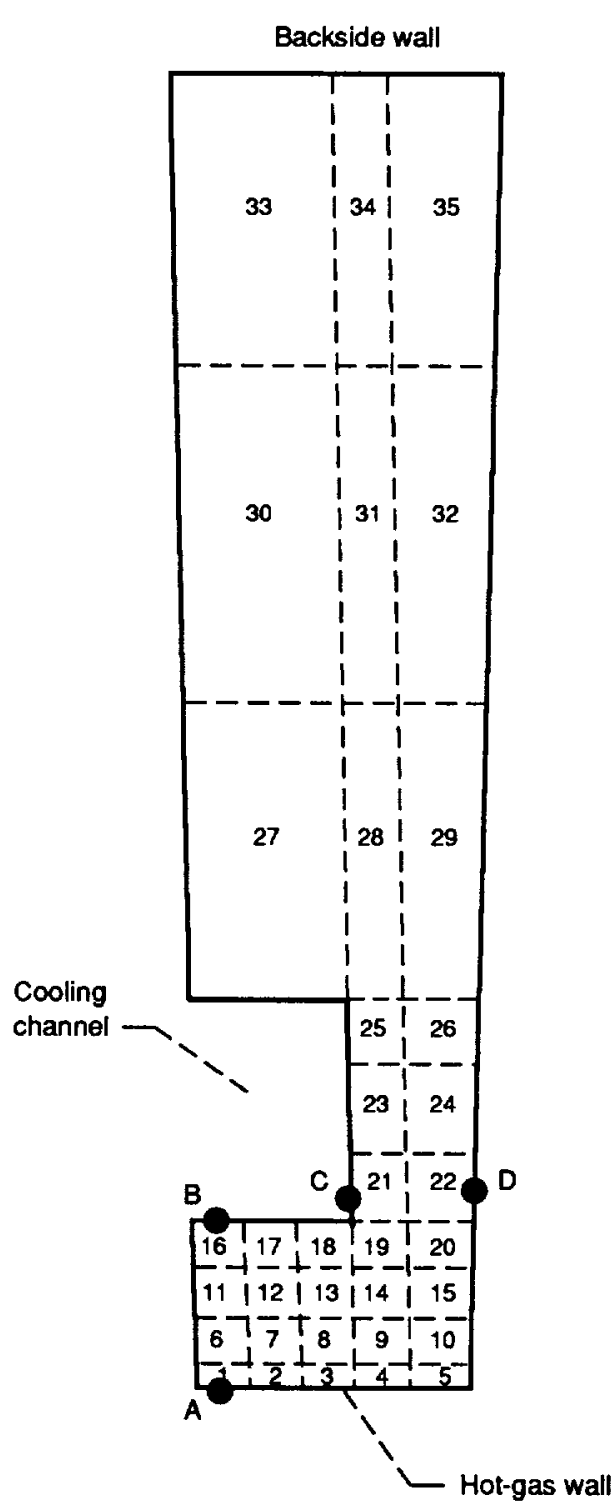

Figure 3. -Finite element model for cylindrical thrust chamber; 35 elements, 54 nodes.

varying nodal temperatures and elemental pressure loadings were applied to trace the loading cycles of table I. Two loading cycles of different durations were used for numerical computations. The short cycle of 3.5-sec duration corresponded to the loading cycles of the experiments. The extended loading cycle of 485.1 -sec duration was typical of SSME operation. The latter cycle offered the opportunity to study the effects of time-dependent creep deformation on the structural response of the cylindrical chamber liner. The nonlinear variations in the temperature-dependent material properties were accounted for in the computations. The temperature distribution obtained from the thermal analysis described in the preceding section was used for the stress analysis. 


\section{Results and Discussion}

\section{Short Loading Cycle}

The circumferential ( $x$-direction) stress distribution in the segment of the component used for the finite element analysis is shown in figure 4 at the completion of the 1st and 12 th short loading cycles. The color figures included in this paper are aimed at providing a quick inference with regard to the tensile or compressive nature of the stress (or strain) distribution in the segment. The stress (or strain) distributions shown in the color figures thus represent the segment's qualitative response to cyclic thermomechanical loading rather than its quantitative response. The circumferential stress is tensile and, in general, decreases with the number of loading cycles. The radial ( $y$-direction) stress distribution is shown in figure 5; here some redistribution of the radial stress with loading cycles is observed in the upper part of the segment. In the lower part of the segment the radial stress remains unaltered at some points, but it increases in magnitude at other points of the segment; for example, in the vicinity of point $B$.

The circumferential ( $x$-direction) and radial ( $y$-direction) mechanical strain distributions in the segment at the end of the 1 st and 12th short loading cycles are shown in figures 6 and 7 , respectively. The circumferential strains are compressive everywhere and are found to increase in magnitude in the neighborhood of points $\mathrm{A}$ and $\mathrm{D}$ with the number of loading cycles. The radial ( $y$-direction) strains are compressive in the segment at the end of the first cycle. Comparison of the radial strain distributions in the segment at the end of the 1st and 12th loading cycles (see fig. 7) shows that the radial strain becomes less compressive with the loading cycles.

The predicted shapes of the segment after the 1 st and 12th short loading cycles are shown in figure 8 . These figures are magnified by a factor of 50 so that the small difference in deformity can be seen.
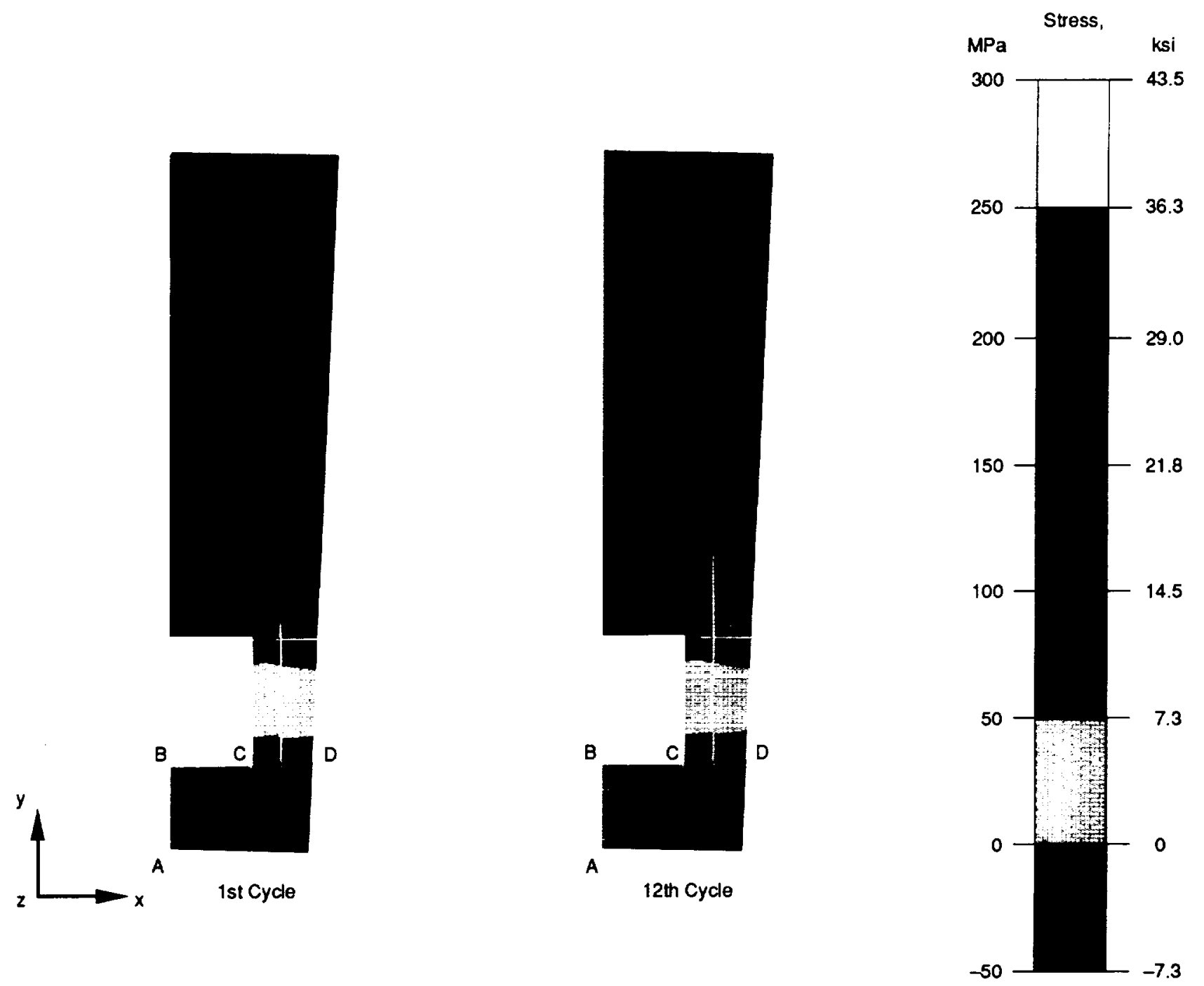

Figure 4.-Short cycle circumferential (r-direction) stress distribution in segment. 

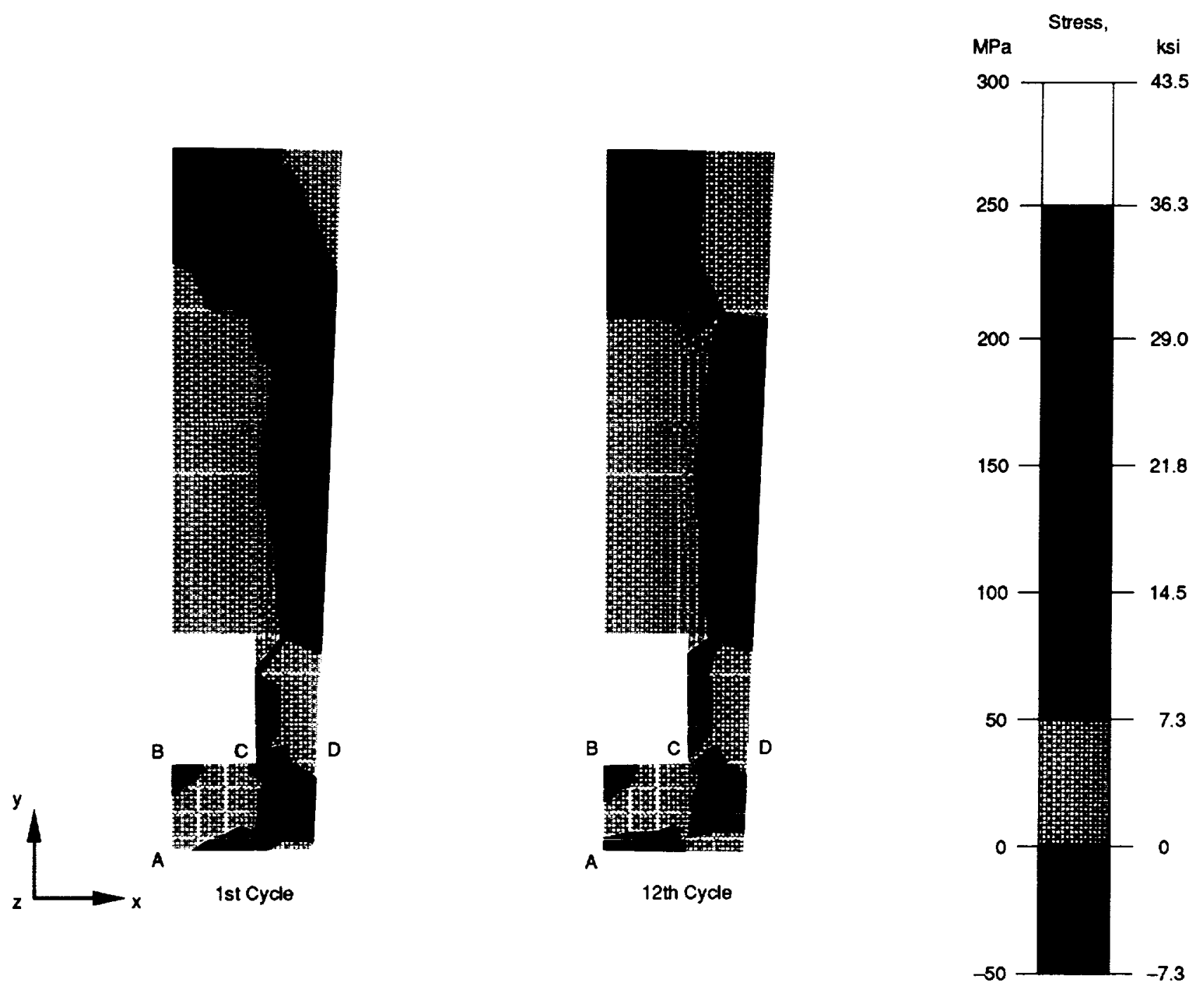

Figure 5.-Short cycle radial ( $y$-direction) stress distribution in segment. 


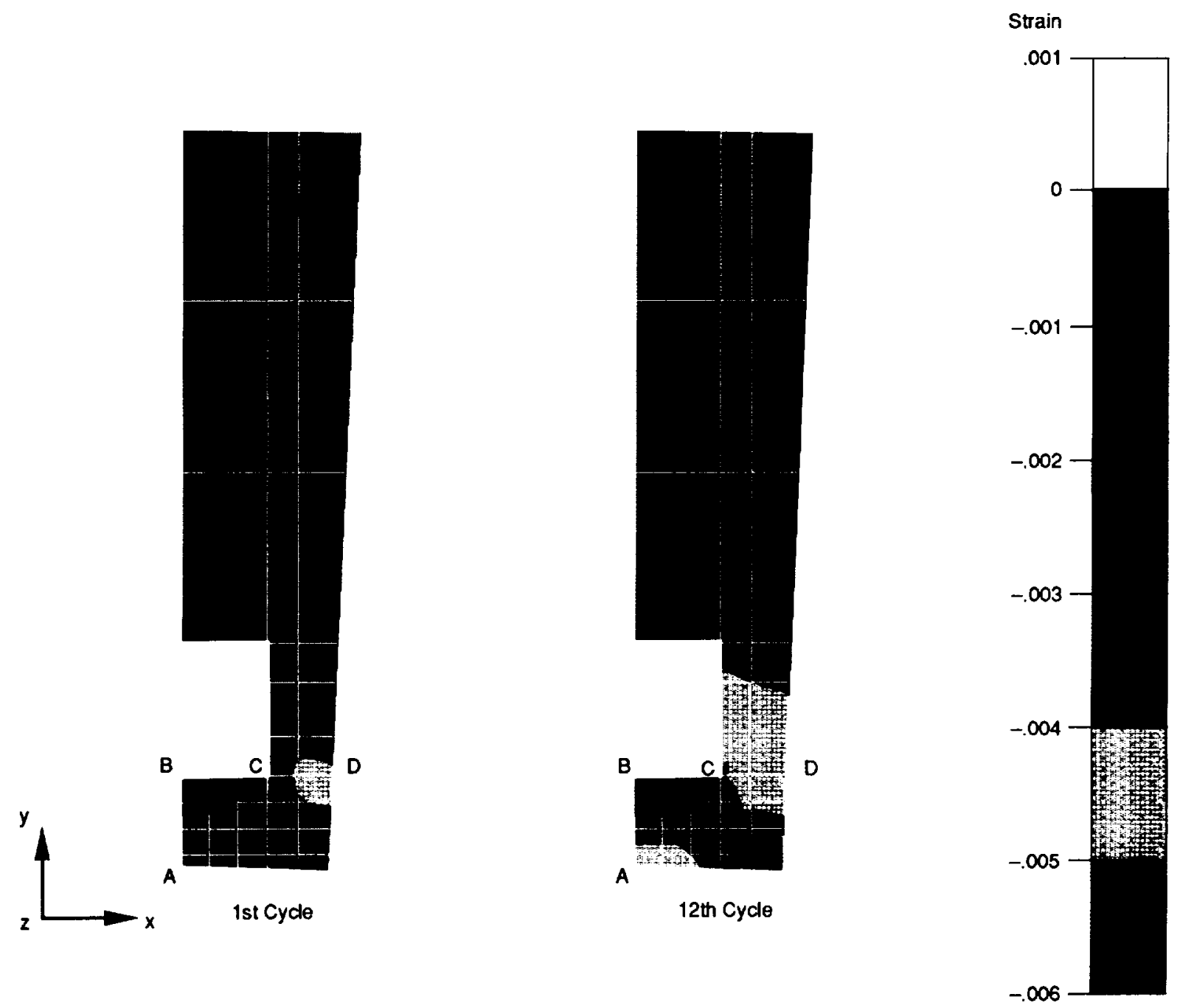

Figure 6.-Short cycle circumferential ( $x$-direction) strain distribution in segment. 


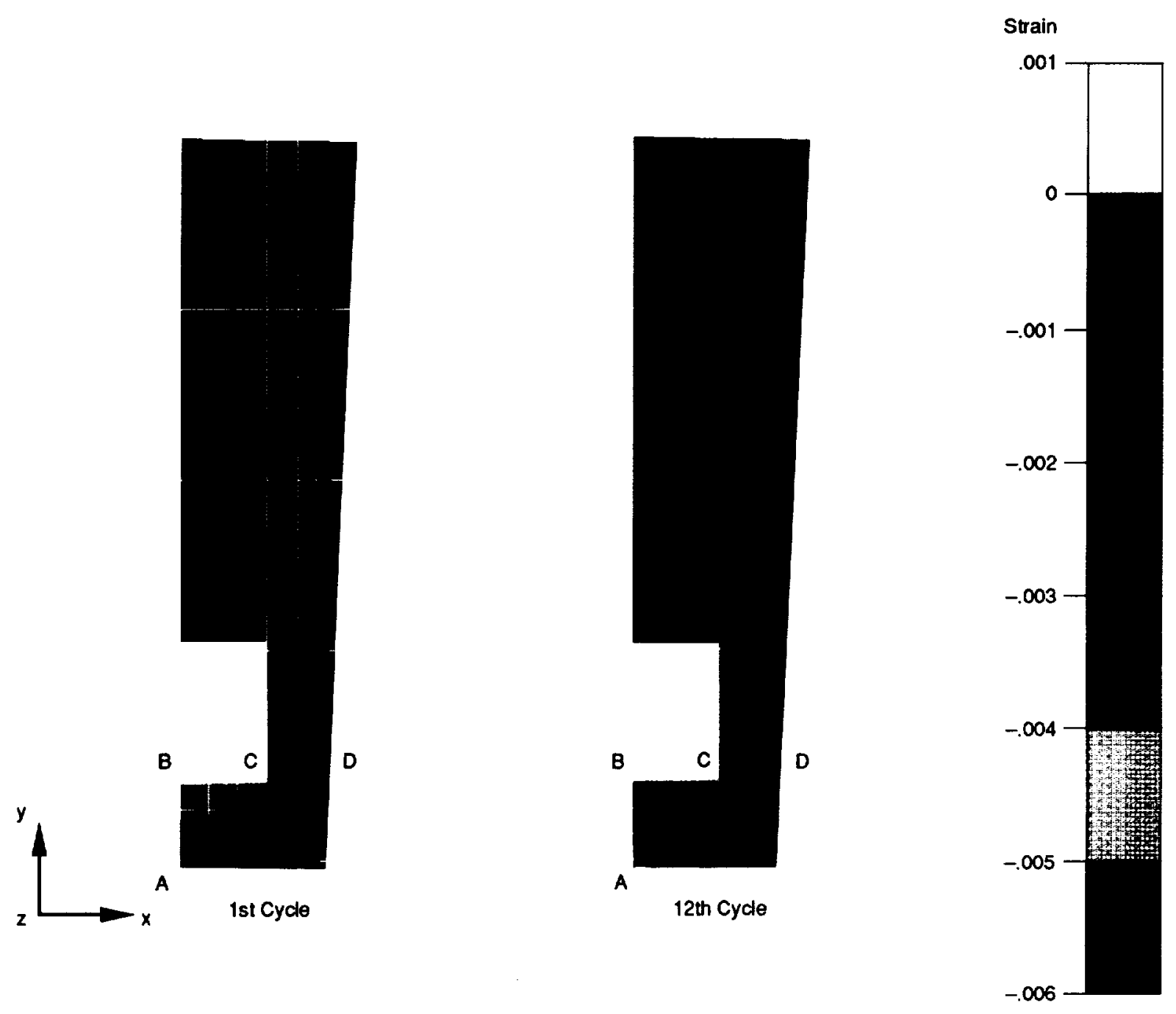

Figure 7.-Short cycle radial ( $y$-direction) strain distribution in segment. 

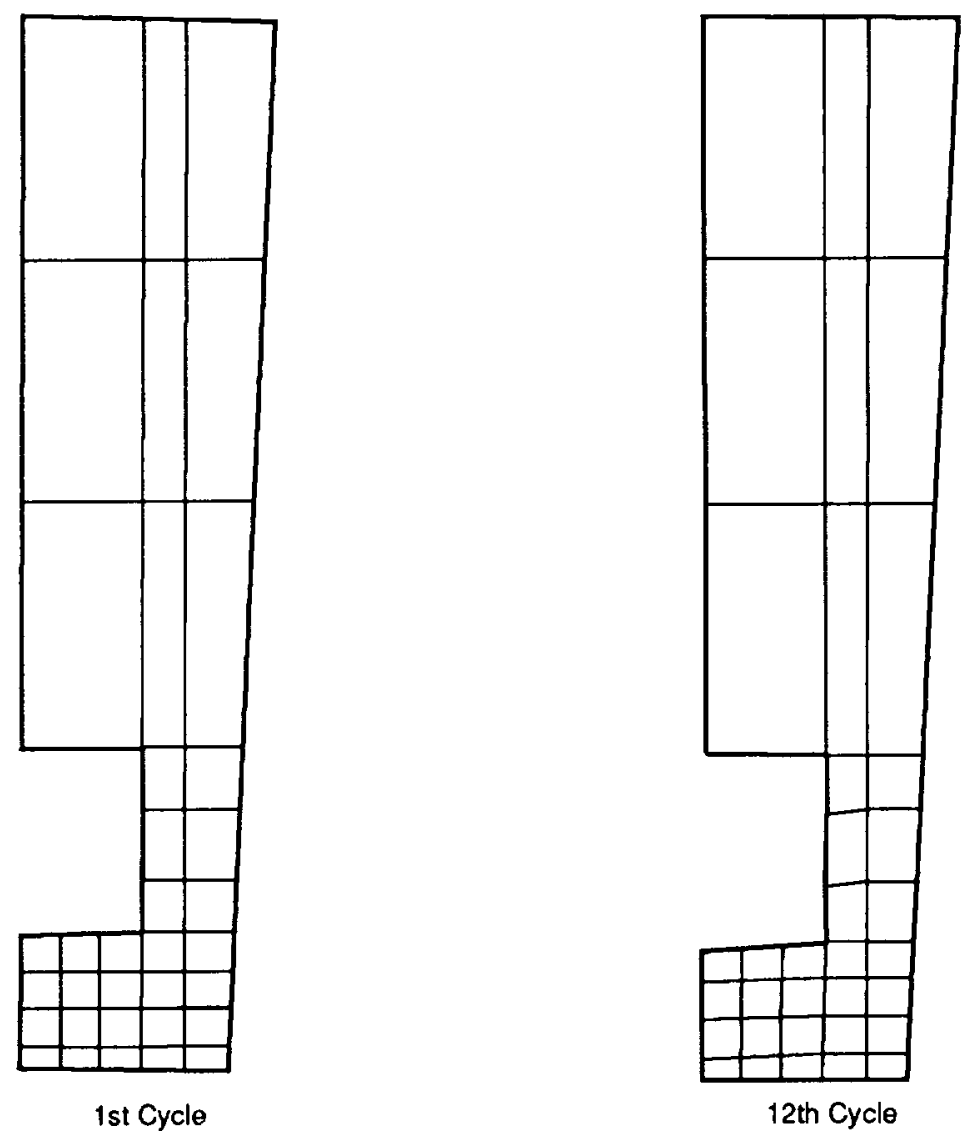

Figure 8. - Predicted shapes of segment after different short cycles (magnification factor $\approx 50$ ). 

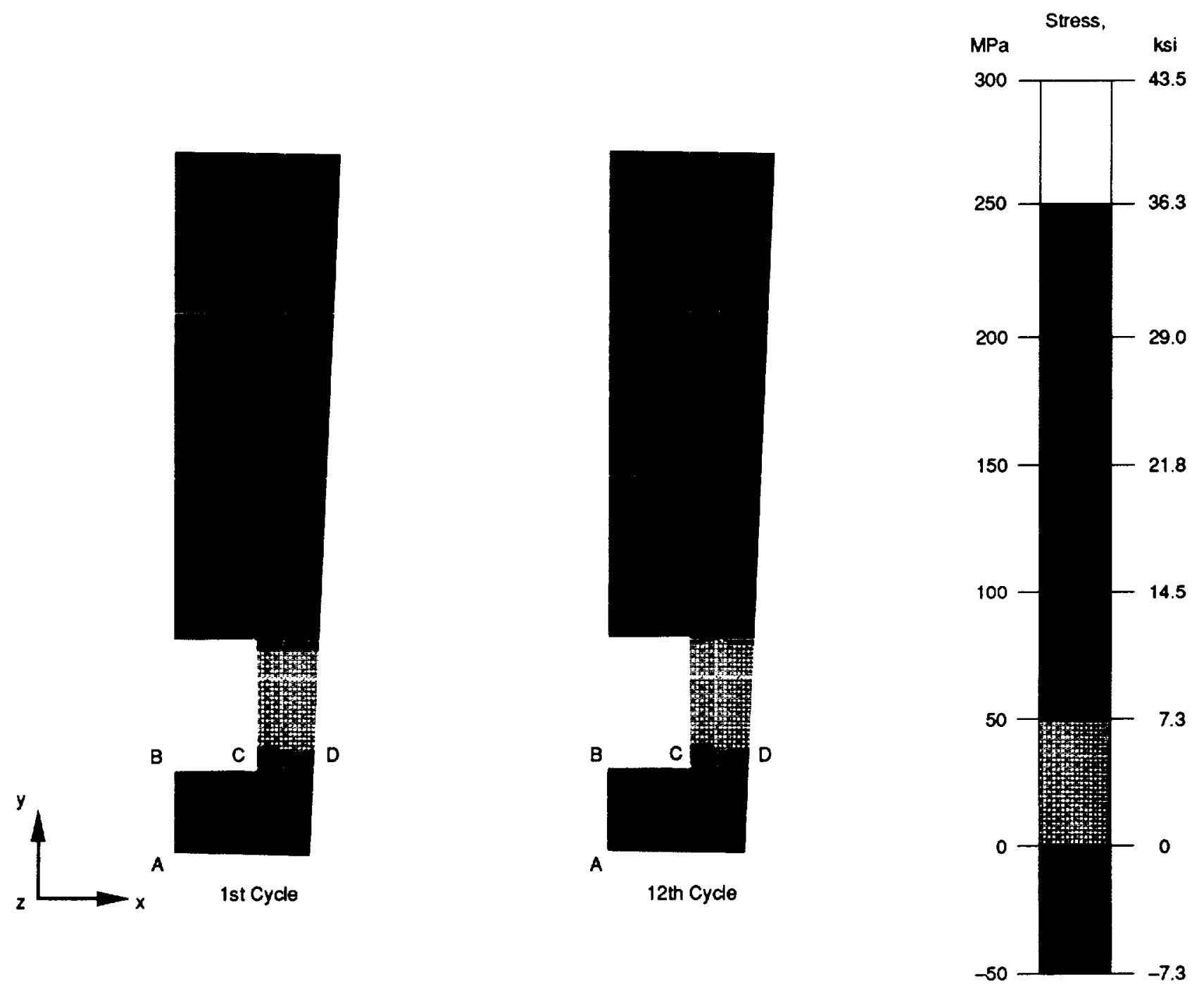

Figure 9.-Extended cycle circumferential (x-direction) stress distribution in segment.

\section{Extended Loading Cycle}

The circumferential ( $x$-direction) and radial (y-direction) stress distributions in the segment at the end of the 1 st and 12th extended loading cycles are shown in figures 9 and 10 , respectively. The circumferential stress is tensile and decreases with the loading cycles. The radial stress either remains unaltered or increases in magnitude with the loading cycles. A comparison of the radial and circumferential stress distributions for the short (figs. 4 and 5) and the extended (figs. 9 and 10) loading cycles shows that, in general, the stress values for the extended loading cycles are lower in magnitude than the corresponding values for the short loading cycles.

Figures 11 and 12 portray the circumferential ( $x$-direction) and radial ( $y$-direction) strain distributions in the segment at the completion of the $1 \mathrm{st}$ and 12 th extended loading cycles.
The circumferential strain increases in magnitude in the lower right part of the segment in the neighborhood of point $D$, whereas it decreases in magnitude in the lower left part of the segment in the vicinity of point $B$ and increases in the neighborhood of point $\mathrm{A}$. The radial strain becomes less compressive with the loading cycles at all points of the segment. The radial strain in the neighborhood of point $D$ changes to tensile (12th cycle) from compressive (1st cycle). A comparison of the strain distribution for the 12th short (fig. 6) and extended (fig. 11) loading cycles reveals that, for the extended cycle, the magnitude of the circumferential strain is lower in the vicinity of points $A$ and $B$ and higher in the vicinity of points $\mathrm{C}$ and $\mathrm{D}$ than it is for the short cycle. The radial strain for the 12th extended loading cycle (fig. 12) is found to be the same or lower in magnitude than that for the short loading cycle (fig. 7) at the corresponding points of the segmentexcept near point $B$, where the trend is reversed. 

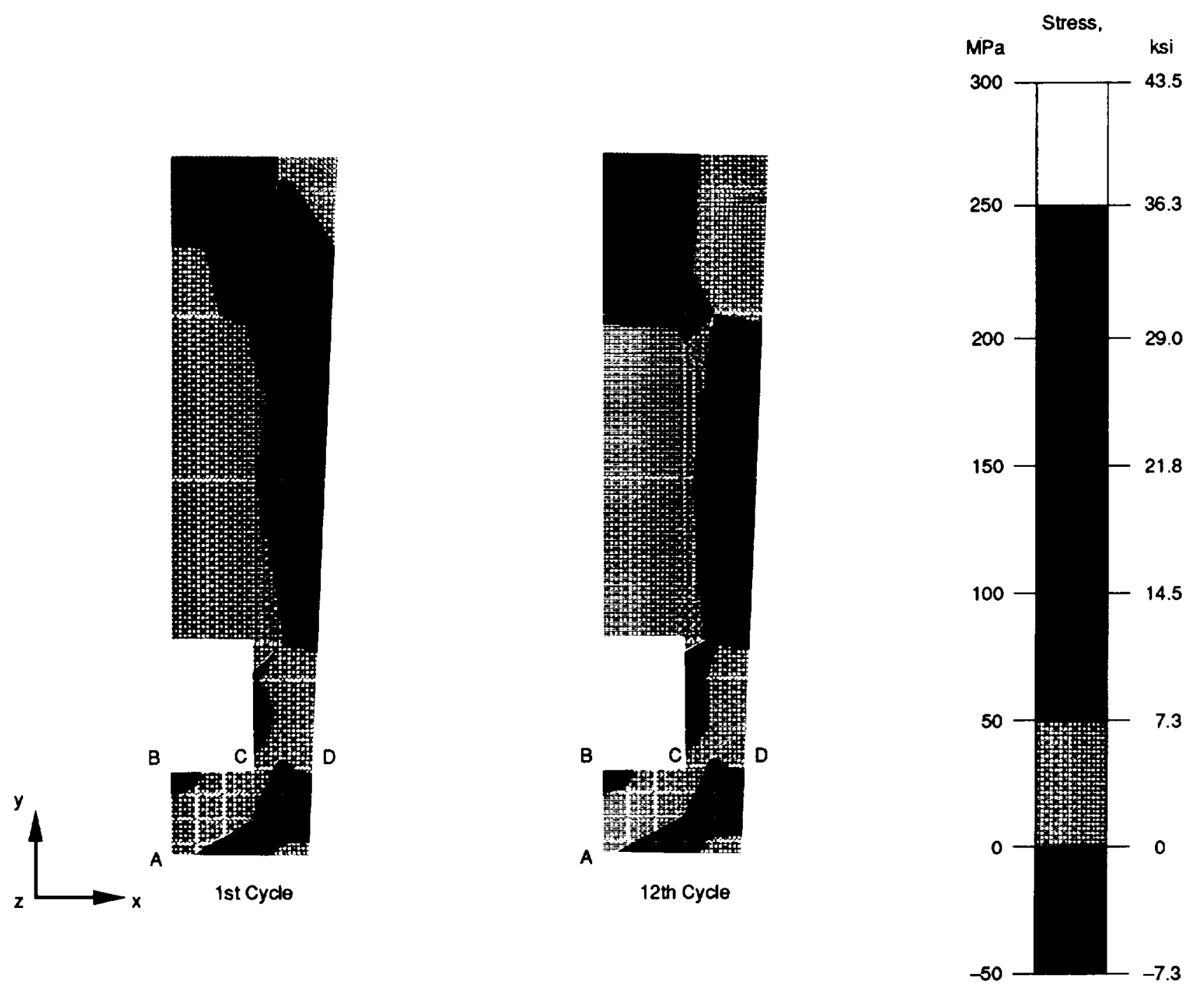

Figure 10.-Extended cycle radial ( $y$-direction) stress distribution in segment. 


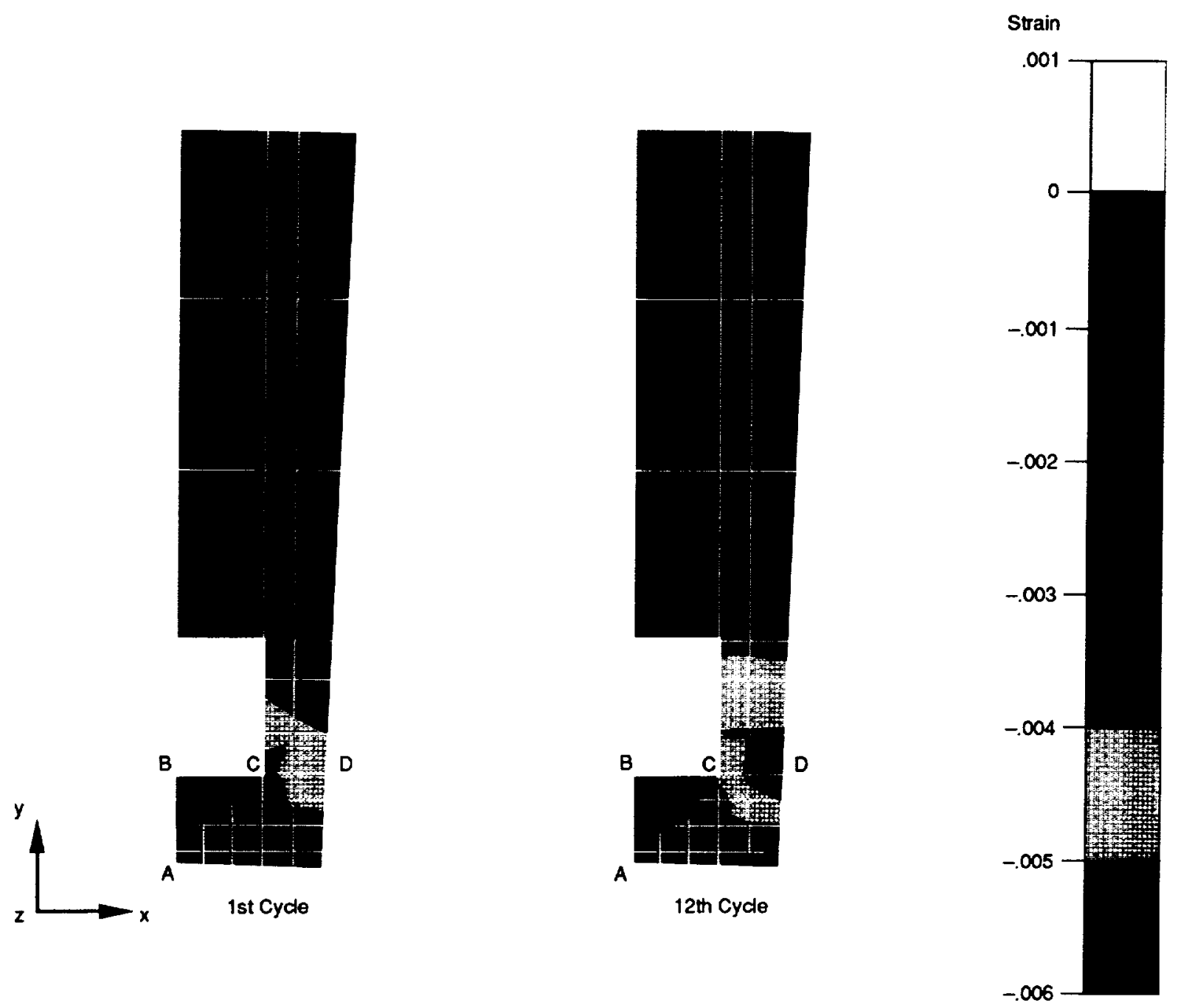

Figure 11.-Extended cycle circumferential ( $x$-direction) strain distribution in segment. 


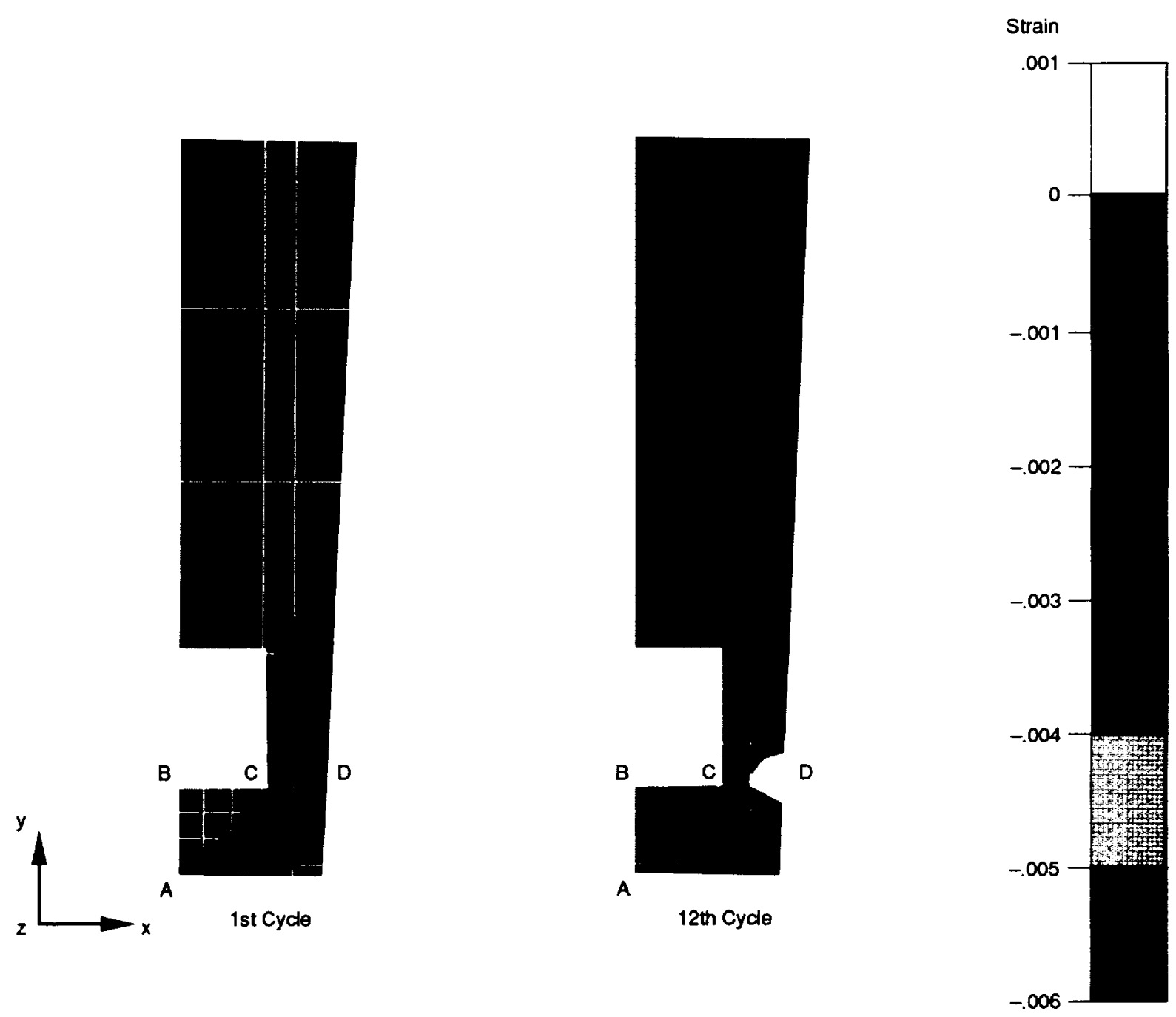

Figure 12.-Extended cycle radial (y-direction) strain distribution in segment.

ORORAL PACE

COLOR HUTCOFH 


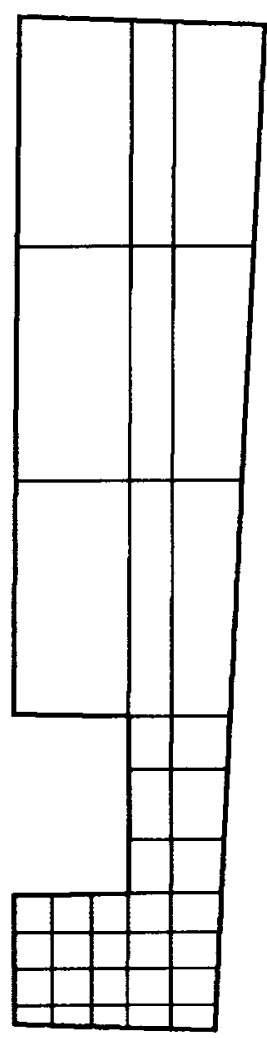

1st Cycle

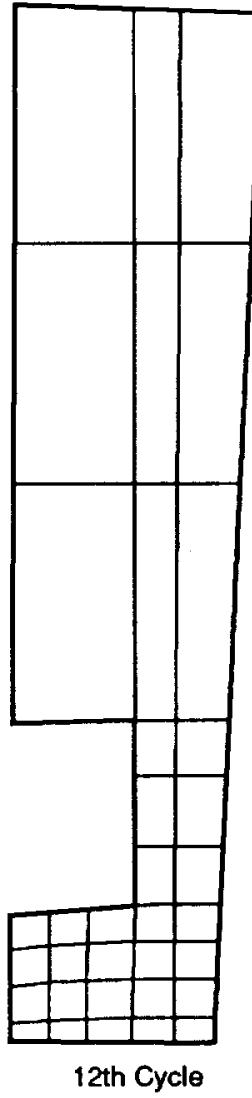

Figure 13.-Predicted shapes of segment after different cycles (extended cycle; magnification factor $\approx 50$ ).

Figure 13 depicts the deformed shapes of the segment after the 1 st and 12 th extended loading cycles. This figure shows noticeable deformation of the coolant-channel wall after the 12 th extended loading cycle.

Figure 14 displays the circumferential ( $x$-direction) displacements at point $C$ of the segment (see inset) as a function of the number of cycles for both the short and extended loading cycles. The displacement values plotted are the values at the completion of the corresponding loading cycle. Since point $\mathrm{D}$ of the segment (which lies in the same horizontal plane as the point $\mathrm{C}$ ) is constrained in this direction, the values shown in figure 14 also give the change in thickness between points $\mathrm{C}$ and D. A comparison of the curves for the short and extended cycles reveals that, for the extended cycle, there is a greater thinning across the section $C D$ of the segment. This fact is supported by examination of the circumferential strain ranges across the section $C D$ for the short and extended loading cycles. Since the strain range for the extended cycle is larger (and compressive), greater thinning of the channel wall across section $C D$ is implied for the extended cycle.

The radial ( $y$-direction) displacements at two locations of the segment (designated by points A and B in the inset) are shown in figure 15 . The displacement values are plotted with respect to the number of cycles. Note that the displacement values at both locations $\mathrm{A}$ and $\mathrm{B}$ are higher in magnitude for the extended loading cycle. This means that the coolant-channel wall bulges out more for the extended cycle than for the short loading cycle. The difference in the displacement values at points $A$ and $B$ is the change in wall thickness (thinning) across the section $A B$ of the segment. The absolute value of this difference, denoted by $\Delta d$, is plotted in figure 16 as a function

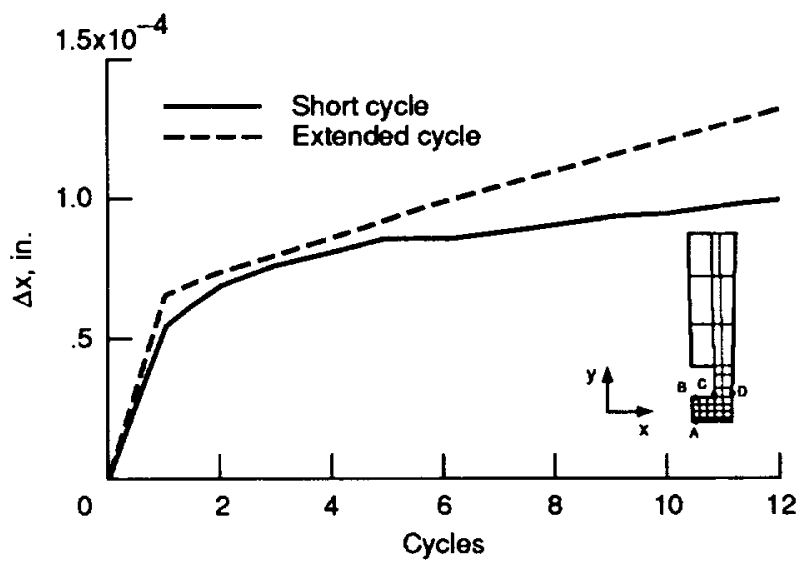

Figure 14.-Decrease in circumferential thickness of segment wall at point $\mathrm{C}$ for both short and extended cycles. 


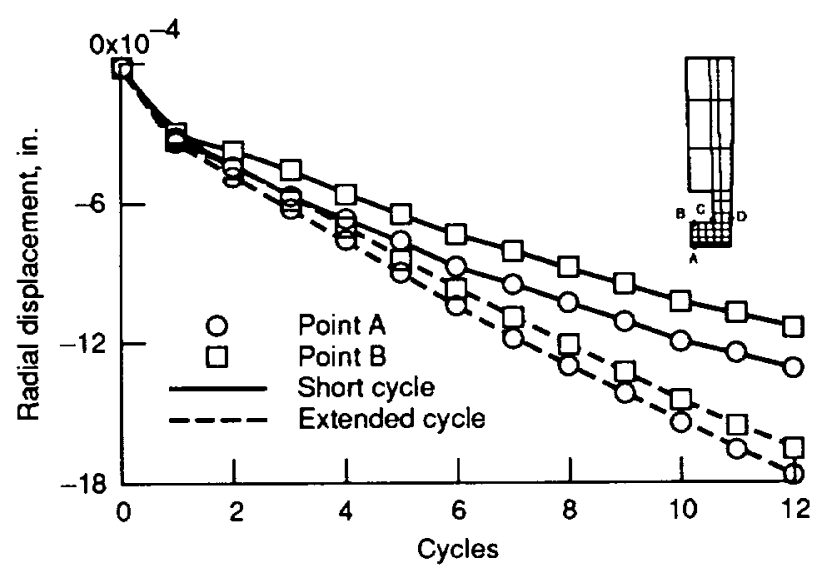

Figure 15.-Radial displacement of points A and B

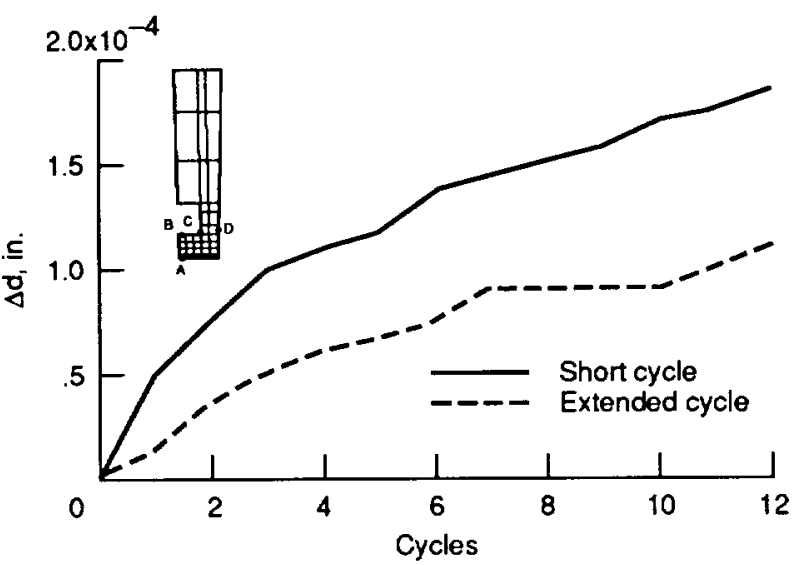

Figure 16.-Decrease in radial thickness across plane AB of segment, for both short and extended cycles.

of the number of cycles. It is interesting to note that the change in wall thickness of the coolant channel (thinning) for the extended loading cycle is smaller than that for the short loading cycle. Close examination of figures 7 and 12 reveals that at the end of 12 th cycle the radial strain range across the section $\mathrm{AB}$ of the segment is smaller for the extended cycle than it is for the short cycle. The strains are compressive. This smaller (compressive) radial strain range indicates a smaller thinning of the coolant-channel wall per cycle for the extended cycle history. Since, for the extended cycle, (1) the displacement values are higher in the radial direction and (2) the wall thinning across section $\mathrm{AB}$ is smaller in the radial direction and larger across section $\mathrm{CD}$ in the circumferential direction than that for the short loading cycle, the failure modes and their location in the segment may be different for the two types of loading cycles.

The circumferential ( $x$-direction) stress distribution in the segment at the hot phase of the 1 st and 12 th extended loading cycles is shown in figure 17 . Figure 18 depicts the corresponding temperature distribution. We can see from figure 17 that, at the hot phase of the 12 th extended cycle, the maximum (in magnitude) circumferential stress is compressive and occurs across section AB. The circumferential stress at the completion of the same cycle (fig. 9) is also at a maximum across section $\mathrm{AB}$, but it is tensile. Since a compressive stress cannot cause the radial cracks seen in the experiments (fig. 3), the cracks (and hence the failure of the segment) are unlikely to occur at the hot end of the cycle. The cracks (and failure) may occur only at the end of the cycle or at the beginning of the next cycle, since the circumferential stress then becomes tensile.

Figure 19 shows the predicted shapes of the NARloy-Z segment at the end of 24 th short and the 4 th extended loading cycles. By employing Robinson's viscoplastic model, we were able to predict the "dog house" effect observed in the experiments of reference 2 (see fig. 2). It is important to note that Robinson's model has only one internal state variable. In an earlier analysis of a copper cylindrical thrust chamber. Arya (ref. 4) employed a viscoplastic model developed by Freed (ref. 16) that incorporated two internal state variables, representing kinematic and isotropic hardening, to predict the "dog house" effect. These results indicate that for the present problem a viscoplastic model with a single internal state variable, representing kinematic hardening, can be successfully employed to predict the experimentally observed behavior. In fact, for a nonisothermal loading cycle such as that used in this work, the isotropic hardening variable in Freed's model saturates quickly; this explains why the two models predict similar deformation behavior of the segment. The predicted shape for the copper thrust chamber at the end of the fourth short loading cycle is also shown in figure 19. This figure shows a larger deformation for the copper chamber than for the NARloy- $Z$ chamber, as would be expected since copper is a softer material than NARloy-Z.

\section{Thermal Loading Cycle}

To assess the role that pressure loading plays on the "dog house" effect, the segment was analyzed by considering thermal loading only. The predicted shapes of the segment at the end of the 1 st and 14th short loading cycles are shown in figure 20. In this figure the segment bulges inward when there is no pressure loading. This implies that the "dog house" effect seen in the experiments and qualitatively predicted from the current viscoplastic analysis is due to the presence of a biasing pressure differential across the coolant-channel wall. Although not shown here, intuitively similar conclusions may be drawn for the extended loading cycle also.

\section{Research Work in Process}

Owing to their light weight and enhanced strength, metalmatrix composite (MMC) materials are becoming increasingly important in aerospace applications. Currently, an MMC cylindrical thrust chamber is being analyzed by using the transversely isotropic viscoplastic model put forth by Robinson (D. N. Robinson, 1989, University of Akron, Akron, Ohio, 

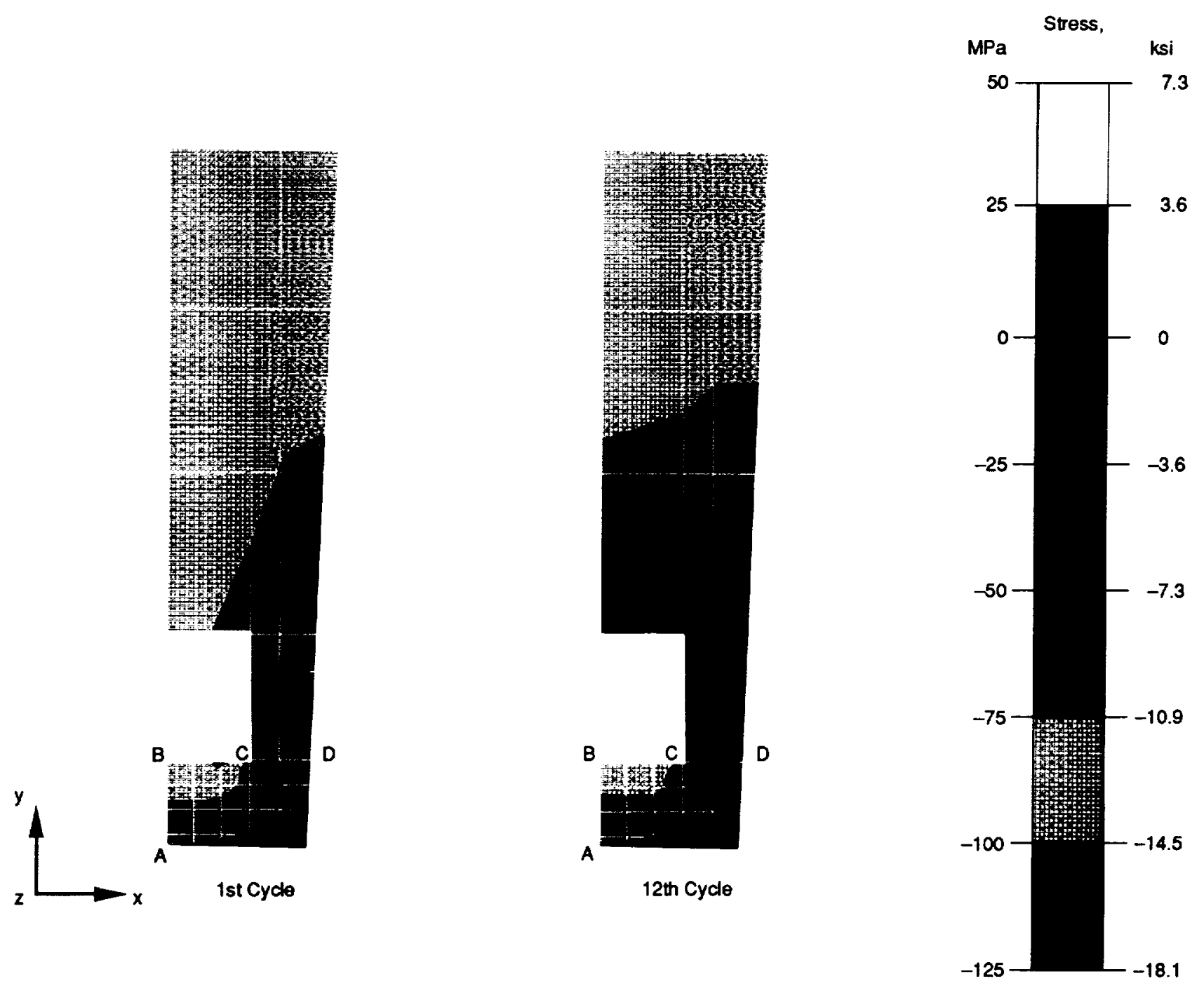

Figure 17,-Extended cycle circumferential (x-direction) stress distribution in segment, for hot phase of cycle. 

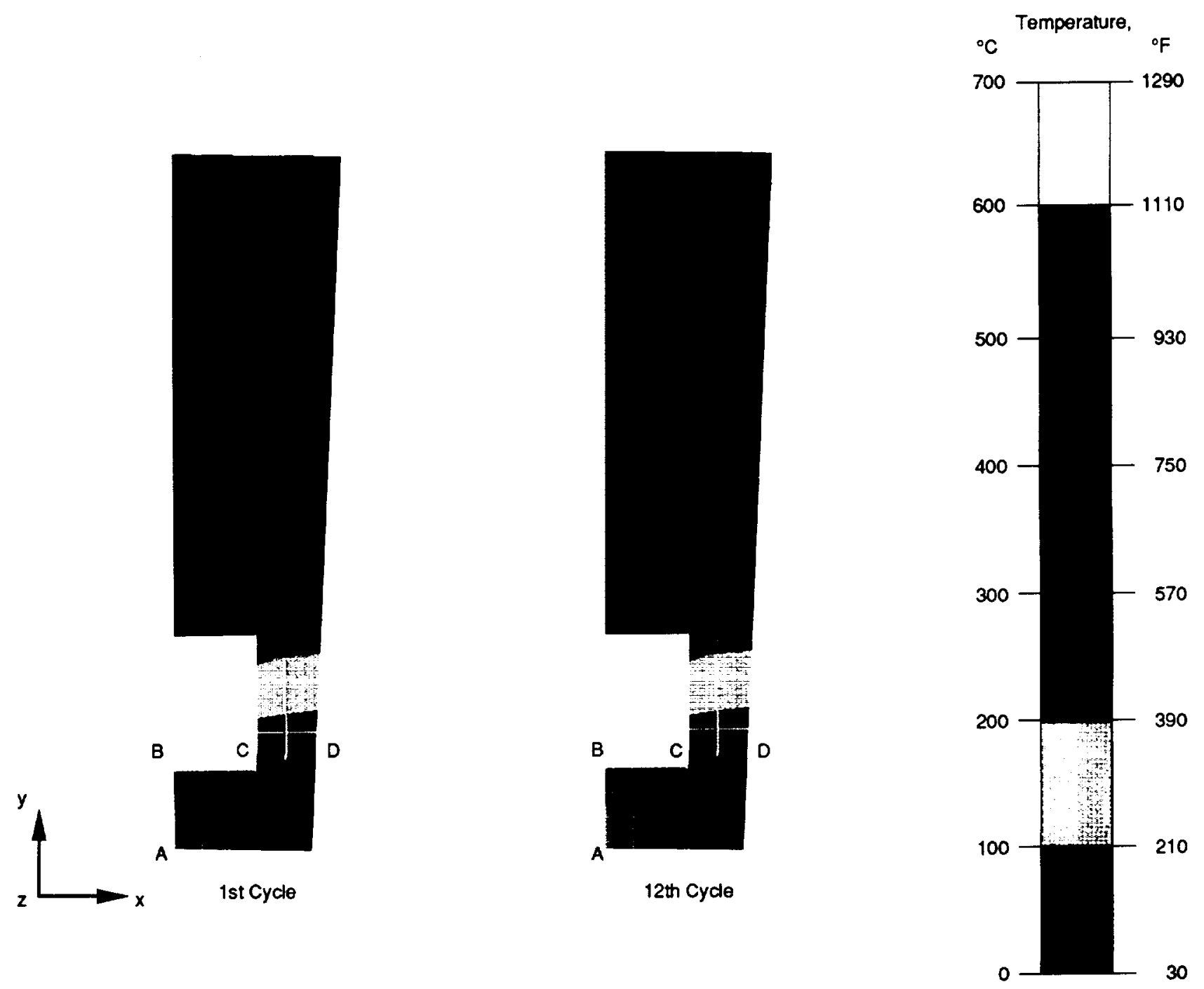

Figure 18.-Extended cycle temperature distribution in segment, for hot phase of cycle.

ORIGINAL PAGE

COLOR FHOTCGRAPH 


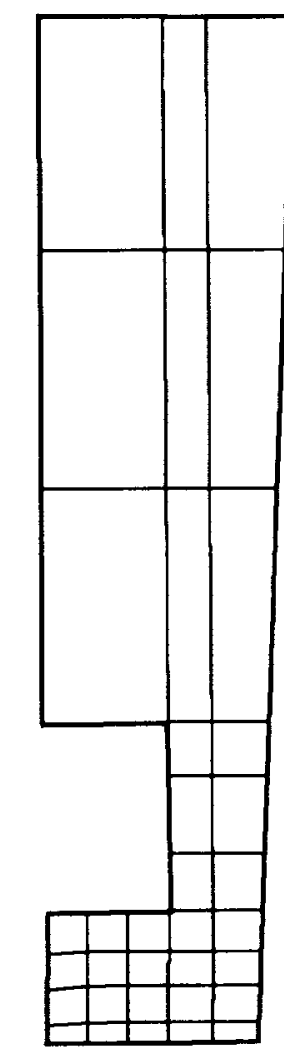

NARloy-Z (24th short cycle)
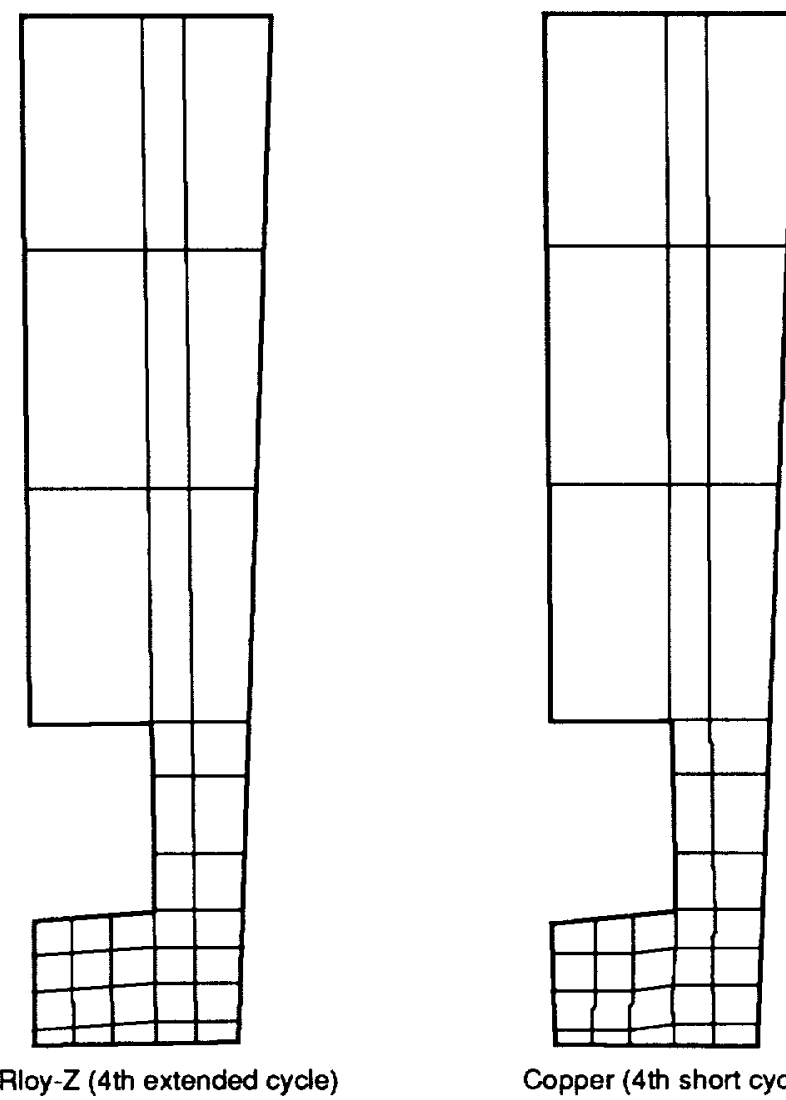

Copper (4th short cycle)

Figure 19.-Comparison of predicted shapes of segments after different cycles (magnification factor $\approx 50$ ). 


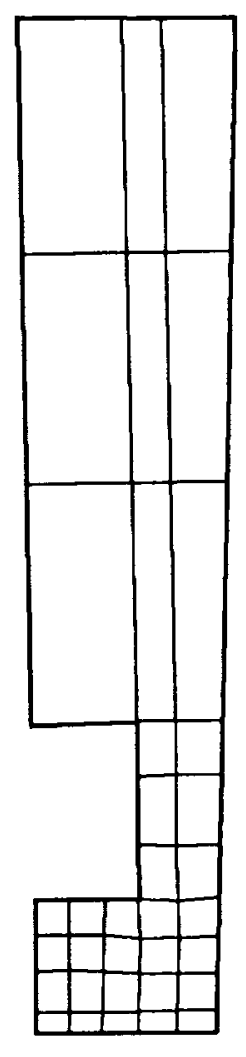

1 st Cycle

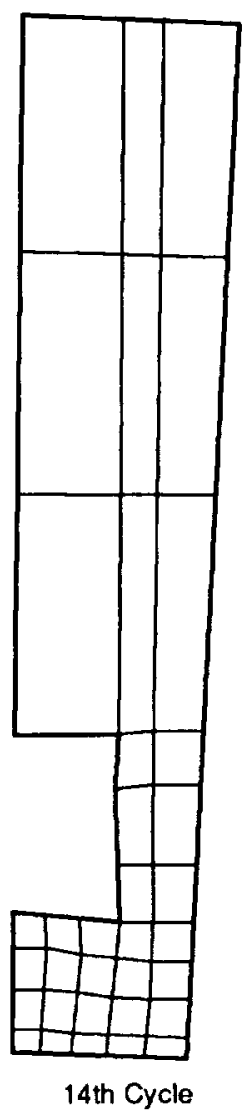

Figure 20.-Predicted shapes of segments owing to thermal loading only (short cycle).

personal communication). Elastic contribution in the model is being calculated by using a transversely isotropic thermoelastic theory put forth by Arnold (ref. 17). The study reported herein was partly motivated by the current MMC thrust chamber analysis since the transversely isotropic model, which is similar to Robinson's isotropic model, incorporates only a single internal state variable. Thus, before analyzing the MMC chamber, we first had to ascertain that the experimentally observed "dog house" and thinning of the coolant-channel wall could be captured with a single internal state variable model. Next, we will analyze the effects and advantages of reinforcing the cylindrical thrust chamber by placing the fibers along different orientations. Then we will try to find the optimum orientation of the fibers - the orientation that would yield the longest service life for the cylindrical thrust chambers.

\section{Conclusions}

A finite element viscoplastic stress-strain analysis for an experimental cyclindrical thrust chamber of NARloy- $Z$ was made by using a viscoplastic model developed by Robinson. Computations were performed for two types of loading cycles. The short cycle of $3.5-\mathrm{sec}$ duration pertained to the experimental situation, whereas the extended cycle of $485.1-\mathrm{sec}$ duration corresponded to the operating cycle experienced by the space shuttle main engine. The analysis qualitatively replicated the "dog house" effect and the thinning of the coolant-channel wall for both the short and extended loading cycles. We noticed the "dog house" effect was caused by the biasing pressure differential across the coolant-channel wall. The location of extensive deformation in the component depended on the duration of the loading cycle, thereby implying that failure of the component may also depend on the duration of the loading cycle. Futhermore, the results showed that structural analysis by a viscoplastic model that incorporates a single internal state variable, representing kinematic hardening, was capable of qualitatively predicting the experimentally observed behavior of the cylindrical thrust chamberas was a viscoplastic model with two internal state variables (Freed's model). 


\section{References}

1. Quentmeyer, R.J.: Thrust Chamber Thermal Barrier Coating Techniques. NASA TM-100933, 1988.

2. Quentmeyer, R.J.: Experimental Fatigue Life Investigation of Cylindrical Thrust Chambers. NASA TM X-7.3665, 1977.

3. Armstrong. M.H.: Structural Analysis of Cylindrical Thrust ChambersFinal Report-Vol. I. NASA CR-159522. 1979.

4. Arya, V.K.: Nonlinear Structural Analysis of Cylindrical Thrust Chambers Using Viscoplastic Models. NASA CR-185253. 1990.

5. Armstrong. M.H.: Structural Analysis of Cylindrical Thrust ChambersFinal Report-Vol. II. NASA CR-165241, 1981.

6. Pugh, C.E.: Background Information for Interim Methods of Inelastic Analysis for High-Temperature Reactor Components of $2 \mathrm{Cr}-1$ Mo Steel. ORNL/TM-5226, 1976.

7. Rubinson, D.N.; and Swindeman, R.W.: Unified Creep-Plasticity Constitutive Equations for $2 \mathrm{Cr}-1 \mathrm{Mo}$ Steel at Elevated Temperature. ORNL/TM-8444, Oct. 1982.

8. Arnold, S.M.: Effects of State Recovery on Creep Buckling Induced by Thermomechanical Loading. Ph.D. Thesis, Akron University, 1987.

9. Arya. V.K.: and Kaufman. A.: Finite Element Implementation of Robinson's Viscoplastic Model and its Application to Some Uniaxial and Multiaxial Problems. Eng. Comput., vol. 6, Sept. 1989, pp. $537-547$
10. Smith, J.P.: Systems Improved Numerical Differencing Analyzer (SINDA): User's Manual. TRW Systems Group. Redondo Beach. CA. TRW14690-H001-R0-00, Apr. 1971.

11. MARC General Purpose Finite Element Program. Marc Analysis Research Corporation, Palo Alto, CA, 1988.

12. Arya, V.K.: Analytical and Finite Element Solutions of Some Problems Using a Viscoplastic Model. Comp. Struct., vol. 33. no. 4. 1989. pp. 957-967.

13. Arya, V.K.: Application of Finite-Element-Based Solution Technologies for Viscoplastic Structural Analyses. NASA CR-185196, 1990.

14. Arya, V.K.; Horngerber K.; and Stamm, H.: On the Numerical Integration of Viscoplastic Models-High Temperature Materials. Report KFK-4082, May 1986.

15. Arya, V.K.: Finite Element Analysis of Structural Components Using Viscoplastic Models With Application to a Cowl Lip Problem. NASA CR-185189, 1990.

16. Freed. A.D.: and Verilli, M.; A Viscoplastic Theory Applied to Copper. NASA TM-100831, 1988.

17. Arnold, S.M.: A Transversely Isotropic Thermolastic Theory. NASA TM-101302, 1989. 


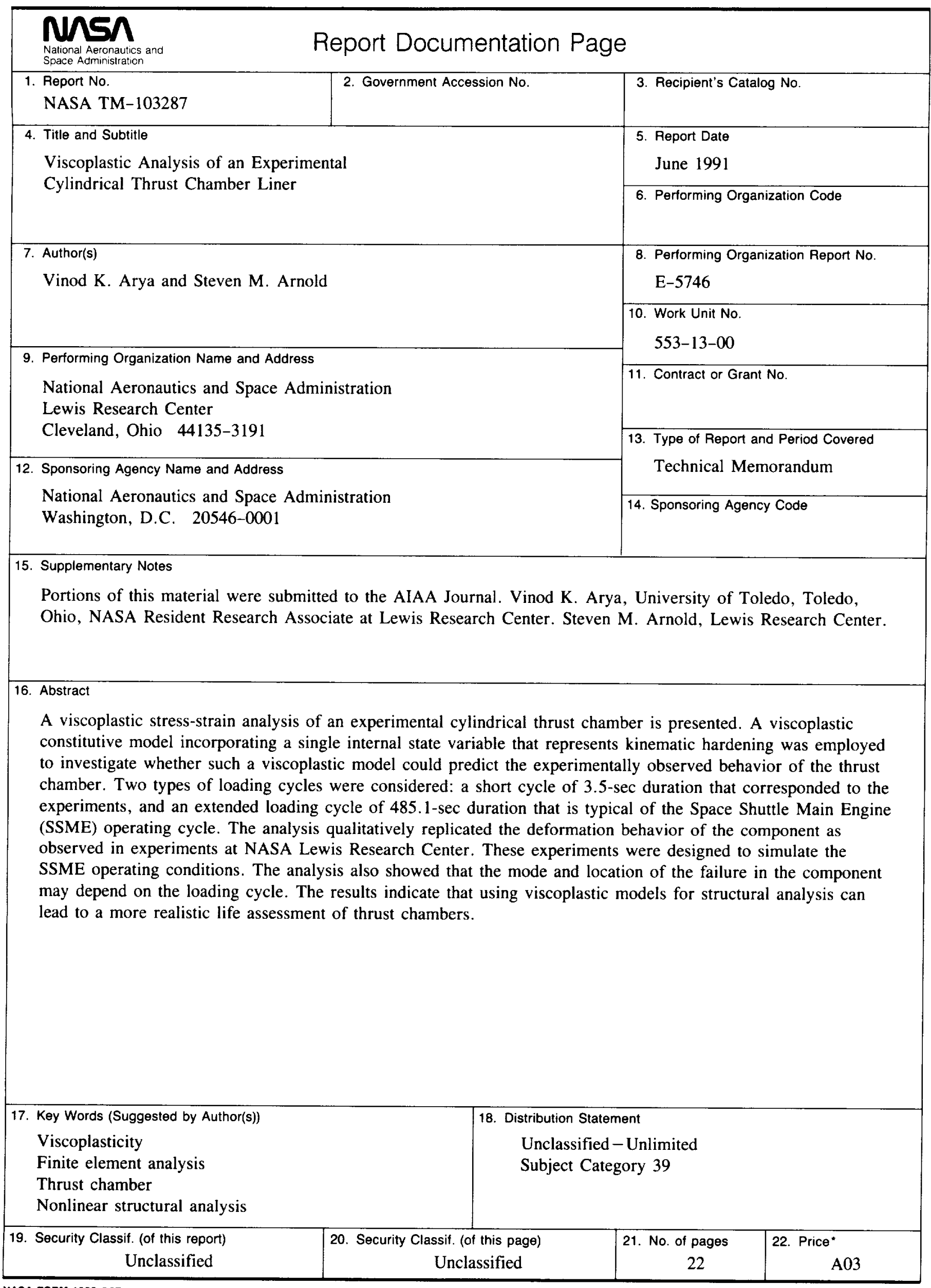


